\title{
Effect of III-health on Technical Efficiency of Food Crop Farmers in Ondo State, Nigeria
}

\author{
Adewuyi Samuel Ayodele ${ }^{1}$, Oladapo Adewale ${ }^{2, *}$, Afolami Carolyn Afolake ${ }^{1}$, Fabusoro Eniola ${ }^{3}$, \\ Oshati Titilola $^{4}$
}

${ }^{1}$ Department of Agricultural Economics and Farm Management, Federal University of Agriculture, Abeokuta, Nigeria

${ }^{2}$ Department of Agricultural Extension and Management, Rufus Giwa Polytechnic, Owo, Nigeria

${ }^{3}$ Department of Agricultural Extension and Rural Development Federal University of Agriculture, Abeokuta, Nigeria

${ }^{4}$ Department of Agricultural Productivity, National Productivity Centre, Abuja, Nigeria

\section{Email address:}

elisam99@yahoo.com (A. S. Ayodele), oladapoadewale14@yahoo.com (O. Adewale), carolynafolami@gmail.com (A. C. Afolake), fabusoroe@funaab.edu.ng (F. Eniola),oshatiti@yahoo.com (O. Titilola)

${ }^{*}$ Corresponding author:

\section{To cite this article:}

Adewuyi Samuel Ayodele, Oladapo Adewale, Afolami Carolyn Afolake, Fabusoro Eniola, Oshati Titilola. Effect of Ill-health on Technical Efficiency of Food Crop Farmers in Ondo State, Nigeria. American Journal of Agriculture and Forestry. Vol. 9, No. 4, 2021 , pp. $183-188$. doi: 10.11648/j.ajaf.20210904.13

Received: January 30, 2021; Accepted: March 2, 2021; Published: June 29, 2021

\begin{abstract}
This study examined the effect of ill-health on technical efficiency of food crop farmers in Ondo State, Nigeria. Primary data were obtained from 300 randomly selected food crop farmers using multistage sampling procedure. Data were analyzed using descriptive statistics and Stochastic Frontier Analysis (SFA). Findings revealed that respondents were still in their economic active age with mean age 46.5 years. Most (82.3\%) of the farmers were male and $44.3 \%$ of the sampled farmers have primary education. Majority (70.0\%) of the respondents had access to health care services out of which $50.7 \%$ had access to government maternity. 58.3 percentage of the respondents lost about 5 farming days due to illness of a member while majority (93.3\%) of the farmers reported ill-health due to malaria, cold and catarrh. Farmers' mean annual expenditure transportation to the nearest health care Centre and medication were $\$ 137.00$ and $\$ 4,228.83$ respectively. Mean technical efficiency was estimated to be 0.627 and the returns to scale computed as the sum of output elasticity for all inputs was estimated as 1.6506, indicating increasing return to scale. SFA showed that travel cost to health care centres $(\mathrm{p}<0.01)$ and cost of disease treatment $(\mathrm{p}<0.05)$ significantly decreased efficiency. The study concluded that cost of disease treatment decreased farmers' efficiency. Therefore, government is encouraged to site health care facilities closer to farmers and ensure that the facilities are adequately equipped with modern medical equipment, drug and trained medical personnel. This should be accessible by farmers to improve efficiency.
\end{abstract}

Keywords: Food Crop, Ill-health, Malaria, Technical Efficiency, Stochastic Frontier

\section{Introduction}

The importance attached to the role of agriculture in Nigeria continued to decline on daily basis due to over concentration on petroleum sector. The Agricultural sector stands to experience more stress because of farmers' illhealth and climate change. It is heart threatening to know that farmers' health adversely affected the sector with notable impacts on production efficiency. The situation is expected to worsen in the near future, if timely intervention with adequate policies that will improve farmers' health are not adopted $[14,18]$. Farmer's ill-health will continue to affect food crop production negatively in developing countries of Africa if not properly managed [5]. According to Moses [17], poor health and disease constitute excessive liability to affected individuals. Though, it is difficulty to measure, the welfare losses to individual who are severely ill can be significant, particularly in developing regions with limited social security provision and health care facilities. Individuals suffering from illness are usually not able to 
provide for dependents due to being weak and unable to work. At a more aggregated level, however, it seems likely that a high disease burden may have an adverse impact on a country's productivity, growth and, ultimately, economic development.

Developing countries need sound health and sustainable agriculture to fight the menace of poverty, because low productivity due to farmers' poor health affects their income and further exacerbate their rate of poverty and ill health [13]. Major illness can cause substantial burden of expenditure to households, making them vulnerable to the extent of liquidating assets, borrowing heavily and pulling further into deep poverty. Moreover, unlike the households with fairly secured permanent source of income, households depending on income from manual casual labour face double burden of health care expenditure in case of illness of working members, direct payment as well as loss of income. Inadequate social security and low levels of income often constrain these households to compromise on necessary duration of treatment. This has lasting effect on worker's health, poverty as well as labour productivity, economic growth, and social welfare. Different specialists measure health status in different ways. The Geneva Based Word Health organization (WHO) defined health as the state of complete physical, mental and social well-being and not merely the absence of disease and infirmity [15, 1]. Good health improves work effectiveness and the productivity of an individual by increasing the physical and mental capacity of people. Though, there are numbers of studies that focused on the associations between health status and economic outcomes, only few concentrated on the improvements in the health of rural agricultural efficiency in the study area. Thus this paper analyzed the effect of ill-health on technical efficiency of food crop farmers in Ondo State, Nigeria.

\section{Methodology}

\subsection{The Study Area}

The study was carried out in Ondo State South West, Nigeria. The state has three distinct ecological zones namely, mangrove forest, rainforest and the Savannah. Data for the study were mainly from primary source. They were collected from rural farmers who are into commonly grown food crops namely: cassava, yam and maize. A multi-stage sampling procedure was adopted in the selection of respondents for the study. The first stage involved the selection of six (6) Local Government Areas out of the 18 local government areas in the study Area (LGAs). The second stage involved a purposive selection of five (5) villages/farming communities from each of the selected local LGAs based on the intensity of farming activities, totaling 30 settlements. The third stage involved a purposeful selection of ten (10) households who were food crop farmers in each farming communities in the study area, totaling three hundred (300) respondents. Structured questionnaire was administered on personal contact with respondents during data collection.

\subsection{Analysis of Data}

Frequency tables and means were used to describe the socio-economics characteristic of respondents and most prevalent diseases causing ill-health. Production efficiency of the food crop farmers was captured with stochastic production frontier.

The function is implicitly defined as follows;

$$
\mathrm{Yi}=\mathrm{f}\left(\mathrm{X}_{\mathrm{i}} \beta\right)+\varepsilon_{\mathrm{i}}
$$

where $Y_{i}$ is cassava output, $X_{i}$ is a vector of inputs, $V_{i}$ is a symmetric error term indicating the effects of pure random factors on production, $\varepsilon_{\mathrm{i}}=\left(\mathrm{V}_{\mathrm{i}}-\mathrm{U}_{\mathrm{i}}\right)$ is the random error term, indicating the effects of inefficiency, it accounted for error and other factors beyond the control of the farmer. $\beta$ is a vector of parameters to be estimated. And technical efficiency (TE) is computed as the ratio of the observed output Yi to the frontier output $Y_{i}^{*}$. That is,

$$
\mathrm{TE}_{\mathrm{i}}=\frac{Y_{i}}{Y_{i}^{*}}
$$

Where,

$\mathrm{TE}_{\mathrm{i}}=$ Technical efficiency of the ith farmer

$Y_{i}=$ Observed output of the ith farmer $(\mathrm{kg})$

$Y_{i}^{*}=$ Potential output of ith farmer $(\mathrm{kg})$

where $0 \leq \mathrm{TE} \leq 1$. The technical inefficiency effects, $\mathrm{U}_{\mathrm{i}}$, are obtained by truncation (at zero) of the normal distribution with mean $\mu_{\mathrm{i}}$ and variance $\sigma_{i}{ }^{2}$ such that:

$$
\mathrm{U}_{\mathrm{i}}=\delta_{0}+\sum_{n=1}^{N} \delta_{n} Z_{n i}
$$

where $Z_{i}$ represents a vector of farm-specific independent variables and $\delta$ is a vector of unknown coefficients of the farm-specific inefficiency effects. Following Battese and Coelli [7], technical efficiencies and their determinants were estimated using a one-step maximum likelihood estimates (MLE) procedure. This is done by incorporating the model for technical efficiency effects into the production function. The use of Cobb-Douglas in technical efficiency studies abound in literature. Following Asefa., Baloyi, et al., Baruwa and Oke., Adewuyi, et al. [6, 8, 9, 2]. The model of CobbDouglas functional form used in this study is explicitly stated as:

$$
\ln \mathrm{Y}_{\mathrm{h}}=\ln \beta_{0}+\beta_{1} \ln \mathrm{X}_{1}+\beta_{2} \ln \mathrm{X}_{2}+\beta_{3} \ln \mathrm{X}_{3}+\beta_{4} \ln \mathrm{X}_{4}+\beta_{5} \ln \mathrm{X}_{5}+\varepsilon
$$

Where:

$\mathrm{Y}_{\mathrm{h}}=$ Value of farm output (Grain equivalent),

$\beta=$ Estimated coefficients,

$\mathrm{X}_{1}=$ farm size (hectares).

$\mathrm{X}_{2}=$ planting material in naira.

$\mathrm{X}_{3}=$ quantity of herbicides (litres).

$\mathrm{X}_{4}=$ labour (man days).

$\mathrm{X}_{5}=$ Fertilizer $(\mathrm{kg})$

$\varepsilon=$ Error term

Technical efficiency measure for individual farm was computed as an index and the average technical efficiency for 
the production system was determined based on the identified socio-economic factors influencing the technical efficiency of the farms, according to Coelli and Battese [10]. The study made use of inefficiency model to evaluate the parameters of the variables. The model assumes that the inefficiency effect $\mathrm{u}_{\mathrm{i}}$ is independently distributed with mean $\mathrm{U}_{\mathrm{i}}$ and variance $\delta^{2}$. The model is specified as:

$$
\mathrm{U}_{\mathrm{i}}=\delta_{\mathrm{o}}+\delta_{1} \mathrm{Z}_{1}+\delta_{2} \mathrm{Z}_{2}+\delta_{3} \mathrm{Z}_{3}+\delta_{4} \mathrm{Z}_{4}+\delta_{5} \mathrm{Z}_{5}+\delta_{6} \mathrm{Z}_{6}+\delta_{7} \mathrm{Z}_{7}+\delta_{8} \mathrm{Z}_{8}+\varepsilon_{\mathrm{i}}
$$

\section{Where}

$\mathrm{U}_{\mathrm{i}}=$ Technical inefficiency

$\mathrm{Z}_{1}=$ Age (years)

$\mathrm{Z}_{2}=$ Household size (Number)

$Z_{3}=$ Farming experience (years)

$Z_{4}=$ Duration of illness (Days absent from farm work due to illness)

$\mathrm{Z}_{5}=$ Cost of travelling to nearest health care center (

$\mathrm{Z}_{6}=$ Cost of Disease Treatment ( $\mathrm{N}$ )

$\delta_{\mathrm{o}}-\delta_{8}=$ Regression estimates

$\varepsilon_{\mathrm{i}}=\mathrm{a}$ random disturbance following half normal distribution

\section{Results and Discussion}

\subsection{Respondents Socio-Economic Characteristics}

Table 1 presents the socio economic characteristics of the respondents in the study area. The table shows that majority of the respondents surveyed for the study were economically active with age ranging between $41-50$ years $(40.70 \%)$ and mean age of 47 years while very few $(5.0 \%)$ are within the age range of 61 years and above. This finding is similar to that of Ambali, et al. [3], in their research work titled," analysis of production efficiency of food crop farmers in Ogun State, Nigeria," they found out that most of the food crop farmers were in their active age of between 35 and 55 years.

Most of the respondents $(82.3 \%)$ were male while only few $(17.7 \%)$ were female. This agrees with the findings of Daudu, et al. [11], in his research work on the effect of gender on farmers' level of involvement in arable crop production activities in Kwara State, Nigeria, who reported that male farmers were more involved in arable crop production activities than their female counterpart in the study area. Most (44.3\%) of the sampled respondents had primary education with about $26.0 \%$ having no formal education. The Table also shows that $93.3 \%$ of the food crops farmers reported ill-health due to malaria. This agrees with the findings of Onuche et al., and Ojo et al. [19, 20], that the most common diseases affecting farmers were malaria, typhoid, aches and diarrhea, evidence from Kogi State, Nigeria. This implies that, these diseases are already causing a setback in farmer's productivity in the study area. Majority $(93.3 \%)$ of the food crop farmers had cold and catarrh while a few $(6.7 \%)$ did not have the disease as at the time of conducting this research.
Table 1. Distribution of respondents by socio-economic characteristics.

\begin{tabular}{llll}
\hline Description & Frequency & Percentage & Mean \\
\hline Age & & & \\
$\leq 30$ & 14 & 4.70 & 46.50 \\
$31-40$ & 76 & 25.3 & \\
$41-50$ & 122 & 40.7 & \\
$51-60$ & 73 & 24.3 & \\
$\geq 61$ & 15 & 5.0 & \\
SEX & & & \\
Male & 247 & 82.3 & \\
Female & 53 & 17.7 & \\
EDUCATION & & & \\
No Formal Education & 78 & 26.0 & \\
Primary Education & 133 & 44.3 & \\
Secondary Education & 80 & 26.7 & \\
Tertiary Education & 7 & 3.0 & \\
MALARIA & & & \\
Yes & 280 & 83.3 & \\
No & 20 & 6.7 & \\
COLD and CATARRH & & 83.3 \\
Yes & 280 & 6.7 & \\
No & 20 & \\
\hline
\end{tabular}

Source: Field Survey Data, 2015

\subsection{Distribution of Respondents According to Access and Availability of Health Care Services}

Table 2, showed that majority (70.3\%) of the respondents have access to health care services while few $29.7 \%$ claimed that they did not have access to health care services. Averagely, (50.7\%) of the farmers affirmed the availability of government maternity or health care center in their communities while ten percentage affirmed the presence of general hospital in their communities. Only $0.7 \%$ and $9.0 \%$ of the farmers make use of private hospital and pharmacy/drug store respectively in their communities. On average, a farmer in the study area spent approximately, $\$ 137.00$ on transportation to the nearest health care Centre in order to receive treatment and paid as much as four thousand two hundred and twenty-eight naira eighty-three kobo ( reported similar result, that cost of illness was as much as 10,744.75 in their study of the effect of health condition on technical efficiency of small-scale crop farmers in Yewa division of Ogun State, Nigeria. This indicated that respondents who are unable to source for money in order to care for themselves during illness may likely die in the course of the diseases. Besides, this amount of money would have been plough back into their farming business if not for the effect of illness. The mean day lost due to illness was estimated to be 6.79, amounting to ( 848.75$)$ man hour. Onuche et al. [19] reported similar result, that farmers in Kogi State loss an average of 8.2 in time available for farm work in a farming season. This loss of days had adversely affected the production efficiency of food crop farmers in the study area. Aminu et al. [4], reported similar occurrence in their research work on the effect of ill health on technical efficiency of dry season vegetable farmers in Ojo Local Government Area of Lagos State Nigeria while Moses [17], reported similar result on the technical efficiency of grain 
farmers in Gombe State, Nigeria.

Table 2. Distribution of respondents according to access and availability of health care Services.

\begin{tabular}{lll}
\hline Description & Frequency & Percentage \\
\hline Access to Health Care Services & & \\
Yes & 211 & 70.0 \\
No & 89 & 29.7 \\
Health Care Facilities & & \\
Non- Availability & 89 & 29.7 \\
General Hospital & 30 & 10.0 \\
Government Maternity & 152 & 50.7 \\
Private Hospital & 2 & 0.7 \\
Pharmacy/Drug Store & 27 & 9.0 \\
Day loss Due to Illness & & \\
$\leq 5$ & 175 & 58.3 \\
10 & 95 & 31.7 \\
15 & 18 & 6.0 \\
$\geq 16$ & 12 & 4.0 \\
\hline
\end{tabular}

Source: Field Survey, 2015.

\subsection{Maximum Likelihood Estimate for Parameters of the Stochastic Frontier Production Function}

Result of the stochastic frontier production function estimate of the effect of ill health on the production efficiency of food crop farmers in the study area is presented in Table 3. The variance parameters of the production function are represented by sigma squared $\left(\delta^{2}\right)$ and gamma $(\gamma)$. The sigma squared value is 4.9165 and significantly different from zero at one percent. This shows a good fit and correctness of the distributional form assumed for the composite error term. The gamma estimate which is 0.3689 shows the amount of variation resulting from the technical inefficiencies of the food crop farmers. This means that 63.11 percent of the variation in food crop farmers output is due to difference in technical inefficiency. Thus on average, the food crop farmers are realizing about $36.89 \%$ of their potential output feasible in the prevailing socio-economics, physical and health environment.

The mean technical efficiency (0.627) of the food crop farmers suggests that farmers can improve their technical efficiency by $37.30 \%$ taken into consideration the current level of technology and the input used

The result of the stochastic production function showed that farmers efficiency was affected by farm size, planting material, herbicides, labour input as well as the socio economic factors: age, household size, education, experience and health status measured as prevalence of diseases, day loss due to illness, cost of travelling to health care centre and cost of disease treatment.

The estimated coefficients of all farm inputs; farm size, planting material, herbicide, labour used in food crop production and fertilizer were positive. This suggests that increase in the use of these inputs would increase output of food crop production. Elasticity of output (0.9198) with respect to farm size is positive and statistically significant at $\mathrm{p}<0.01$ alpha level. This implies that, farm size is a significant factor that influences the output of food crop farmers. Hence, increasing farm size by one percent will increase output by $91.98 \%$ depending on the management of the farm.

Coefficient of the variable of planting material was 0.2655 and significant at $\mathrm{P}<0.01$ alpha level, thus, a percentage increase in the variable of planting material will increase output by $26.55 \%$. The coefficients of the variable of herbicide, labour and fertilizer were positive but not statistically significant. This is in conformity with the findings of Egbetokun et al. [12], in their field survey on farmers' health and technical efficiency in Osun State, Nigeria, they, reported that the farm inputs used during crop production; land, labour, fertilizer and insecticides were positively related to output. The returns to scale which is the addition of output elasticity for all inputs was estimated as 1.6506 , indicates an increasing return to scale.

Table 3. Parameters Estimates of Cobb-Douglas Stochastic Frontier Production Function for the effect of ill-health on production efficiency of arable crop farmers in the study Area.

\begin{tabular}{|c|c|c|c|}
\hline Variables & Parameters & Coefficient of Stochastic frontier & t-value \\
\hline Constant & $\beta_{0}$ & $5.1025 * * *$ & 3.5893 \\
\hline Farm size $\left(\mathrm{X}_{1}\right)$ & $\beta_{1}$ & $0.9198 * * *$ & 3.7942 \\
\hline Planting Material $\left(\mathrm{X}_{2}\right)$ & $\beta_{2}$ & $0.2655 * * *$ & 3.6732 \\
\hline Herbicide $\left(\mathrm{X}_{3}\right)$ & $\beta_{3}$ & 0.1787 & 1.1524 \\
\hline Labour $\left(\mathrm{X}_{4}\right)$ & $\beta_{4}$ & 0.0636 & 0.6354 \\
\hline Fertilizer $\left(\mathrm{X}_{5}\right)$ & $\beta_{5}$ & 0.2230 & 1.2940 \\
\hline \multicolumn{4}{|l|}{ INEFFICIENCY MODEL } \\
\hline Age & $\delta_{1}$ & $-0.3557 * * *$ & -3.8387 \\
\hline Household Size & $\delta_{2}$ & $-0.3484 *$ & -1.6421 \\
\hline Experience & $\delta_{4}$ & $0.2485 * * *$ & 3.8233 \\
\hline Day loss due to Illness & $\delta_{6}$ & 0.1315 & 1.0416 \\
\hline Travel Cost to Health Centre & $\delta_{7}$ & $0.0127 * * *$ & 3.7232 \\
\hline Cost of Disease Treatment & $\delta_{8}$ & $0.0008 * *$ & 2.5310 \\
\hline \multicolumn{4}{|l|}{ DIAGNOSTIC STATISTICS } \\
\hline Gamma & $\Gamma$ & $0.3689 * * *$ & 2.2357 \\
\hline Mean Technical Efficiency & & 0.6269 & \\
\hline
\end{tabular}

Source: Field Survey, 2015. *** Variable significant at 1\%,** Variable significant at $5 \%$ and * Variable significant at $1 \%$. 


\subsection{Technical Inefficiency Measurement of Food Crop Farmers}

The existence of technical inefficiency provides a sound ground to find out the sources of inefficiencies among food crop farmers in the study area. The result of the technical inefficiency is presented in Table 3. Estimated coefficients of the number of days' loss due to illness, travel cost to health Centre, and cost of disease treatment were positive while food crop farmers' age and household size were negatively correlated to inefficiency. The coefficient for age variable is negative and statistically significant at $\mathrm{P}<0.01$. This shows that as farmers age increases, more experience is gained in food crop farming, thereby resulting into increase in the efficiency of food crop farmers in the study area. The coefficient for household size variable is estimated to be negative and statistically significant at $\mathrm{P}<0.10$. This implies that increase in household size tend to increase farmers' efficiency. Farmers experience was positive and significant at $1 \%$ alpha level, indicating that these variables decrease farmer's efficiency in the study area. Though, this is contrary to a priori expectation, however, the result could be due to the fact that experience gained by farmers are not in food crop production.

The coefficient of the variables of ill-health measured by (day loss due illness, cost of travelling to the nearest health care center and cost of disease treatment) were positive. However, only the coefficient of the variables of travel cost to the nearest health care center and cost of diseases treatment were significant at (1\% and 5\%) probabilities level respectively while the coefficient of the variable of travel cost to the nearest health care center was positive and significant at $(\mathrm{P}<0.01)$. This indicated that increase in the cost of transportation to health care center decreases farmer's efficiency. The table also reveals that cost of disease treatment (i.e Cost of medication) also have positive correlation with farmer's inefficiency and significant at five percent. An increase in farmers cost of medication rises inefficiency of the food crop farmers. This follows a priori expectation, that ill-health decreases technical efficiency of the farmers. This agrees with the findings of Munongo and Chitungo., Ojo et al. [16, 19], that adverse health and household sizes have positive effects on inefficiency of the farmers.

\subsection{Frequency Distribution of Efficiency Analysis of Food Crop Farmers}

The result on Table 4 showed the frequency distribution of technical efficiency analysis of the food crop farmers. The technical efficiency differs substantially among the food crops farmers as it ranges from $0.030-0.863$. The mean TE was estimated to be 0.627 . This implies that there is a potential of about $37.3 \%$ for the food crop farmers to improve their output. Approximately $(13.0 \%)$ of the food crop farmers have technical efficiency index below the mean $62.7 \%$ while $48.0 \%$ attained technical efficiencies above the mean. The reasons for the variation in technical efficiency was due to inadequate management of the food crop farms due to health challenges of the farmers.

Table 4. Distribution of food crop farmers by technical, economic and allocative efficiency

\begin{tabular}{lll}
\hline Technical Efficiency & Frequency & Percentage \\
\hline$\leq 0.10$ & 7 & 2.3 \\
$0.11-0.20$ & 15 & 5.0 \\
$0.21-0.30$ & 9 & 3.0 \\
$0.31-0.40$ & 14 & 4.7 \\
$0.41-0.50$ & 19 & 6.3 \\
$0.51-0.60$ & 32 & 10.7 \\
$0.61-0.70$ & 48 & 16.0 \\
$0.71-0.80$ & 117 & 39.0 \\
$0.81-0.90$ & 39 & 13.0 \\
Mean Technical Efficiency & 0.627 & \\
\hline
\end{tabular}

Source: Field Survey, 2015.

\section{Conclusion and Recommendations}

This research examines the effect of ill-health on technical efficiency of arable crop farmers in Ondo State Nigeria. The descriptive analysis showed that food crop farmers in the study area are economically active with majority of the respondents experiencing ill-health due to malarial, cold and catarrh. The stochastic frontier production function estimate showed that inefficiency exist among the food crop farmers. The food crop farmers were operating between the boundary of stage one and two of the production response surface. Travel cost to the nearest health care center and cost of disease treatment were found to decrease food crop farmer's efficiency.

Government is encouraged to make treated mosquito net available to farmers at a subsidized rate as a measures of reducing the effect of malaria. In other to reduce cost of transportation, government should cite health care facilities closer to the food crop farmers and ensure that the facilities are adequately equipped with modern medical equipment, drug and trained medical personnel. Furthermore, farmers should be encouraged to check their health status on regular basis to know their health status early enough before sickness degenerate beyond what can be managed with little amount of money. This will help in reducing cost of medication and financial burden of diseases treatment on the farm family.

\section{References}

[1] Adekunle, A. K., Adekunle, C. P., \& Aihonsu, J. O. Y. (2016). Effect of Health Condition On Technical Efficiency of SmallScale Crop Farmers in Yewa Division of Ogun State, Nigeria. Nigerian Journal of Agriculture, Food and Environment. 12 (2): 138-143.

[2] Adewuyi, S. A., Agbonlahor, M. U., \& Oke, A. T. (2013). Technical efficiency analysis of cassava farmers in Ogun state, Nigeria. International Journal of Agriculture and Food Security (IJAFS), 4: 515-522. 
[3] Ambali, O. I., Adegbite, D. A., Ayinde, I. A., \& Awotide, D. O. (2012). Analysis of Production Efficiency of Food Crop Farmers in Ogun State, Nigeria, ARPN Journal of Agricultural and Biological Science, 7 (9) 680-688.

[4] Aminu, F. O., Ayinde, I. A., \& Ambali, O. I. (2013). Effect of Ill Health on Technical Efficiency of Dry Season Vegetable Farmers in Ojo Local Government Area of Lagos State Nigeria. World Journal of Agricultural Research, Vol. 1, No. 6, 108-113 http://pubs.sciepub.com/wjar/1/6/3

[5] Ajani, O. I., \& Ugwu, P. C. (2008). Impact of Adverse Health on Agricultural Productivity of Farmers in Kainji Basin NorthCentral Nigeria Using Stochastic Production Frontier Approach. Trends in Agricultural Economics 1 (1): 1-7.

[6] Asefa, S. (2011). Analysis of technical efficiency of crop producing smallholder farmers in Tigray, Ethiopia. MPRA Paper No. 40461, posted 6. Available at http://mpra.ub.unimuenchen.de/40461/.

[7] Battese, G. E., \& Coelli, T. J. (1983). A model for technical inefficiency effects in a stochastic frontier production function for panel data. Empirical Economics 20: 325-332.

[8] Baloyi, R. T., Belete, A., Hlongwane, J. J., \& Masuku, M. B. (2012). Technical efficiency in maize production by smallscale farmers in Ga-Mothiba of Limpopo province, South Africa. African Journal of Agricultural Research, 7: 54785482 .

[9] Baruwa, O. I., \& Oke, J. T. O. (2012). Analysis of Technical Efficiency of Smallholder Cocoyam Farms in Ondo State, Nigeria. Tropicultura, 30: 36-40.

[10] Coelli, T., \& Battese, G. (1996). Identification of factors which influence the technical inefficiency of Indian farmers. Australian Journal of Agricultural Economics, 40 (2), 103 128.

[11] Daudu, A. K., Matanmi, B. M., Oladipo, F. O., Aliyu, A. S., \& Olatinwo, L. K. (2015). Effect of Gender on Farmers' Level of involvement in Arable Crop Production Activities in Kwara State, Nigeria. Journal of Production Agriculture and Technology, 11 (2). 10-19.
[12] Egbetokun, O. A., Ajijola, S., Omonona, B. T., \& Omidele, M. A. (2011). Farmers' Health and Technical Efficiency in Osun State, Nigeria International Journal of Current Research 4 (1): 11-17.

[13] IFPRI. (2007). Micro-Level Analysis of Farmers' Adaptation to Climate Change in Southern Africa, Discussion Paper 00714.

[14] Justus, O., Lilian, K., \& Mary, M. T. (2016). Effect of Climate Variability and Change on Agricultural Production: The case of Small Scale Farmer in Kenyan. NJAS-Wageningen Journal of Life Sciences Vol. 77 Pp 71-78.

[15] McMahon, R. E., Barton, M., Piot, N., Geling \& Ross, F. (1992). A Guide to Management in Primary Health Care on Being in Charge (2end Edn.) WHO Geneva, Switzerland, pp: $1-4$.

[16] Munongo, S., \& Chitungo, K. S. (2013). The Impact of Farmers' Health and Nutritional Statuson Agricultural Technical Efficiency: Evidence from Masvingo Rural Communities, Journal of Agriculture and Sustainability 3 (1): $1-15$.

[17] Moses, D. J. (2017). Effect of Ill Health on Technical Efficiency of Grain Farmers in Gombe State, Nigeria. International Journal of Innovative Food, Nutrition and Sustainable Agriculture 5 (4): 7-14.

[18] Oladapo, A., \& Afolami, C. A. (2019). Effect of Credit Use on Technical Efficiency of Cassava Farmers in Ondo State, Nigeria. Proceedings of the $33^{\text {rd }}$ National Conference of the Farm Management Association of Nigeria (FAMAN) October $7^{\text {th }}-10^{\text {th }} 2019$. Pp 234-240.

[19] Ojo, A. O., Akande N. O., Tanko L., \& Ojo M. A (2018). Analysis of Ill-Health and Technical Efficiency of Maize Farmers in Selected Local Government Areas of Osun State, Nigeria. Journal of Research in Forestry, Wildlife \& Environment Vol. 10 (3): 81-91.

[20] Onuche, U., Opaluwa, H. I., \& Edoka, M. H. (2014). Ill Health and Agricultural Production: Evidence from Kogi State of Nigeria, African Journal of Food Agriculture, Nutrition and Development 14 (1): 8488-8503. 